\title{
Overexpression of KH-type splicing regulatory protein regulates proliferation, migration, and implantation ability of osteosarcoma
}

\author{
DUMNOENSUN PRUKSAKORN ${ }^{1,2}$, PIMPISA TEEYAKASEM $^{1}$, JEERAWAN KLANGJORHOR $^{1}$, \\ PARUNYA CHAIYAWAT $^{1}$, JONGKOLNEE SETTAKORN ${ }^{3}$, PENCHATR DISKUL-NA-AYUDTHAYA ${ }^{5}$, \\ DARANEE CHOKCHAICHAMNANKIT ${ }^{5}$, PERAPHAN POTHACHAROEN ${ }^{4}$ and CHANTRAGAN SRISOMSAP $^{5}$ \\ ${ }^{1}$ Department of Orthopedics, Faculty of Medicine, Orthopedic Laboratory and Research Netting Center (OLARN Center), \\ ${ }^{2}$ Excellence Center in Osteology Research and Training Center (ORTC), \\ ${ }^{3}$ Department of Pathology, ${ }^{4}$ Thailand Excellence Center for Tissue Engineering and Stem Cells, \\ Department of Biochemistry, Faculty of Medicine, Chiang Mai University, Chiang Mai 50200; \\ ${ }^{5}$ Biochemistry Laboratory, Chulabhorn Research Institute, Bangkok 10210, Thailand
}

Received April 12, 2016; Accepted June 15, 2016

DOI: 10.3892/ijo.2016.3601

\begin{abstract}
Osteosarcoma is a common malignant bone tumor in children and adolescents. The current 5-year survival rate is $\sim 60 \%$ and that seems to be reaching a plateau. In order to improve treatment outcomes of osteosarcoma, a better understanding of tumorigenesis and underlying molecular mechanisms is required for searching out possible new treatment targets. This study aimed to identify the potential proteins involving the pathogenesis of osteosarcoma using a proteomics approach. Proteins extracted from primary cell culture of osteosarcoma $(n=7)$ and osteoblasts of cancellous bone $(n=7)$ were studied. Using 2-DE based proteomics and LC-MS/MS analysis, we successfully determined seven differentially expressed protein spots. Four upregulated proteins and three downregulated proteins were observed in this study in which KH-type splicing regulatory protein (KSRP) was selected for further exploration. KSRP was significantly upregulated in osteosarcoma cells compared to osteoblasts using western blot assay. In addition, immunohistochemistry demonstrated that KSRP was also highly expressed in osteosarcoma tissue of independent cases from the experimental group. More importantly, KSRP silencing of osteosarcoma cell lines significantly decreased cell proliferation, migration ability, as well as implantation and growth ability in chick chorioallantoic membrane assay. Taken together, these findings demonstrate, that KSRP plays important roles in regulatory controls of osteosarcoma pathogenesis and serves as a potentially therapeutic target of osteosarcoma.
\end{abstract}

Correspondence to: Dr Dumnoensun Pruksakorn, Department of Orthopedics, Faculty of Medicine, Orthopedic Laboratory and Research Netting Center (OLARN Center), Chiang Mai University, 239 Suthep Road, Chiang Mai 50200, Thailand

E-mail: dumnoensun.p@cmu.ac.th

Key words: FUBP2, KSRP, osteosarcoma, pathogenesis, proteomics

\section{Introduction}

Osteosarcoma is a common malignant bone tumor in children and adolescents. This disease presents as a bimodal age peak distribution, that is, 0-24 years and $>60$ years. Incidence in youth (0-24 years) is similar across the world at $\sim 3.4$ patients per million (1). Current treatment, based on surgery and chemotherapy, provides a 5-year survival rate of $\sim 60 \%$. However, that survival rate seems to have reached a plateau since 1980 (2). In order to improve treatment outcomes, the challenge is to develop a better understanding of tumorigenesis and to search for new targets or strategies of treatment.

The pathophysiology of disease initiation and progression in osteosarcoma is still unclear. There is no specific risk factor predisposing for this disease (3), the peak incidence has been shown to be related to secondary growth (1). No specific genetic abnormality patterns for disease predilection have been identified, although there is a high incidence of osteosarcoma related to the mutation of p53, RB and the RECQ-Helicase family (4). The epigenetics and protein regulatory controls has become a focus for identifying common pathways in the various steps of pathological events. Some agents which related to these have been studied as potential targets in experimental and clinical trials scale (5).

Proteomics describes global changes in the expression patterns of proteins under different biological conditions. Notably, there is still a lack of information regarding the proteomic profile of osteosarcoma since the preparation of proteins under properly matched condition is limited. Heterogeneous tissue, consisting of various cellular and matrix content, causes uncertain results of proteomic analysis. Furthermore, there is a lack of validated information on some potential proteins from proteomic studies in clinical samples due to the disease being relatively rare.

In order to determine pathogenesis-related proteins in osteosarcoma, proteomics serves as a valuable tool for identifying differentially expressed proteins between primary osteosarcoma and osteoblast cells, which were derived from 
primary biopsy of osteosarcoma patients and normal cancellous bone of non-cancer participants, respectively. Expression levels of candidate protein was further validated in both osteosarcoma cell culture system and tissue specimens. Importantly, we also explored biological roles of candidate protein with progressive behavior of osteosarcoma. This study reveals a possibly therapeutic target of osteosarcoma from proteomics study of well-characterized primary cells.

\section{Materials and methods}

Study design and participant recruitment protocol. Proteomics study was carried out from primary cell osteosarcoma and osteoblasts in order to identify the proteins involving in pathogenesis. Primary cells were extracted from chemo-naïve osteosarcoma tissue of 7 patients (osteosarcoma cell), and normal cancellous bone of 7 participants (osteoblast cells). Using 2-DE based proteomics approach, there were 49 biologically different sets in this experiment. A fold-change of more than two times the initial threshold for screening protein spots of all 49 match sets. A consistently up- or downregulated match was determined when the spots presented in the same direction (up or down) in $>70 \%$ of all match sets. The consistently up-or downregulated spots were subjected to tryptic In-gel digestion and LC-MS/MS analysis. Candidate spots were determined when they had the statistically significant difference of percent volume between osteosarcoma and osteoblast. The selected protein was validated and tested for the possibility to be the potential therapeutic targets. Patients, or parent of patients, and participants gave consent before being recruited into the study. All research protocols were approved by the Ethics committee of the Faculty of Medicine, Chiang Mai University, Thailand, EC no. ORT-11-09-16A-14 (ID\#757).

Primary osteosarcoma and osteoblastic cell isolation, and cell characterizations. The tissue (naïve chemotherapy) was immediately subjected to primary cell extraction after biopsy. Primary osteosarcoma cells were extracted by incubating minced tissue in $5 \mathrm{mg} / \mathrm{ml}$ collagenase type I solution (Gibco, MA, USA) at $37^{\circ} \mathrm{C}$ for $18 \mathrm{~h}$. The cells were then isolated by centrifugation and cultured in 10\% FBS-DMEM (Gibco). The healthy participants were patients who had been diagnosed with other, non-cancer, orthopedic conditions, and required the use of an autologous bone grafts for substitution procedure. Some bone graft was immediately subjected to perform osteoblast extraction after harvested. Osteoblasts were isolated with sequential collagenase type I-trypsin digestion. The cells were isolated and expanded in $10 \%$ FBS-DMEM $(6,7)$. The cells from the 2-4 passages were used for cellular characterization, proteomics study, and protein validation. Doubling time of primary cells was estimated using proliferation analysis by using a hemocytometer with time-course measurement. Molecular marker expression was monitored by quantitative real-time polymerase chain reaction (RT-PCR) (8). Collagen type I, osteonectin, bonesialoprotein were selected as the osteogenic markers. MMP-9, collagen type $X$ were selected as the cancer markers (7). Alkaline phosphatase (ALP) activity assay was conducted kinetically by monitoring the conversion of $p$-nitrophenyl phosphate ( $p$ NPP) to $p$-nitrophenol (9). Alizarin red-S histo- chemistry was performed to measure mineralization ability (10). Activity of MMP-9 in the culture media was measured by gelatin zymographic assay (11).

Real-time polymerase chain reaction. Total RNA was isolated using an Ilustra RNAspin Mini kit (GE Healthcare, UK), and cDNA was synthesized from total RNA using a Bioline SensiFAST $^{\mathrm{Tm}}$ cDNA synthesis kit (Bioline, UK). Real-time PCR was performed using cDNA as a template under standard conditions with Taq DNA polymerase (Bioline). The RT-PCR was carried out using a Bioline SensiFAST ${ }^{\text {TM }}$ SYBR $^{\circledR}$ No-ROX kit (Bioline). A Chromo4 ${ }^{\mathrm{TM}}$ Real-Time PCR Detection system (Bio-Rad, CA, USA) was used to detect cDNA amplification levels. Relative expression levels were normalized to the expression of $G A P D H$ or $18 S-R N A$ by the $2^{-\Delta \mathrm{CT}}$ method (8). The primer sequences used in this experiment were follows: GAPDH, 18S-RNA, Collagen type I, osteonectin, bonesialoprotein, MMP-9, collagen type $X$ and $K S R P$, respectively. F, 5'-GAAGGTGAAGGTCGGAGTC-3' and R, 5'-GAAGATGGTGATGGGATTTC-3'; F, 5'-CTT AGAGGGACAAGTGGCG-3' and R, 5'-ACGCTGAGC CAGTCAGTGTA-3'; F, 5'-CAGCCGCTTCACCTACAGC-3' and R, 5'-TTTTGTATTCAATCACTGTCTTGCC-3'; F, 5'-TCTATGTTAGCACCTTGTCTCCAG-3' and R, 5'-CAG CCGCTTCACCTACAGC-3'; F, 5'-GCAGTAGTGACT CATCCGAAGA-3' and R, 5'-GCCTCAGAGTCTTCATCTT CATTC-3'; F, 5'-TGAGAACCAATCTCACCGACAG-3' and R, 5'-TGCCACCCGAGTGTAACCAT-3'; F, 5'-AGCCAG GGTTGCCAGGACCA-3' and R, 5'-TTTTCCCACTCCAG GAGGGC-3'; F, 5'-CCGCCTACTACTCACACTACTA-3' and R, 5'-TCTTCCCAGGCCTTAGTGTA-3'.

Protein extraction, 2-DE and visualization of spots, and In-gel Tryptic digestion. Primary osteosarcoma and osteoblast cells were cultured until reaching their $90 \%$ confluence. Cells were washed with PBS, scraped in $5 \mathrm{ml}$ of $0.25 \mathrm{M}$ sucrose containing protease inhibitor cocktail 1:500 (Sigma, MO, USA) and spun down. Three hundred microliters of lysis buffer was added into the cell pellet, then, cell suspension was incubated on ice and separated by a sonicator. Cellular debris was removed, and the protein concentration in supernatant was quantified by Bradford assay kits (Bio-Rad) (12).

Protein analysis was performed with 2-DE, and the setup conditions including the first dimension electrophoresis, the second dimension electrophoresis, gel scanning and software analysis were conducted as described briefly (12). For the first dimension, Immobiline ${ }^{\mathrm{TM}}$ drystrip, $7 \mathrm{~cm}$, non-linear, $\mathrm{pH}$ 3.0-10.0 gradient and immobilize $\mathrm{pH}$ gradient (IPG) gel strips were used. The first dimension of gel electrophoresis was run on Ettan IPGphor III system. Total $150 \mu \mathrm{g}$ proteins with $75 \mu \mathrm{l}$ of rehydration buffer was loaded into IPG strip and incubation in Immobiline Drystrip Re-swelling Tray. The current application was $50 \mathrm{~mA}$ per IGP gel strip and the four running conditions as shown in literature (12). Two equilibration steps were performed before subjecting to the second dimension. For the second dimension, the proteins were separated on $12.5 \%$ SDS gel with $4 \%$ stacking SDS gel. For the running program, i) current $10 \mathrm{~mA} / g e l$ for $15 \mathrm{~min}$, and ii) current $20 \mathrm{~mA} / \mathrm{gel}$ until the bromophenol blue reached the end of the gel. Finally, the gels were submerged in the coomassie blue 
solution overnight and de-stained with $50 \%$ (v/v) methanol, $10 \%(\mathrm{v} / \mathrm{v})$ acetic acid (12). Gels were scanned and the background adjusted by using Ettan labscan 5.0. Next, the images were analyzed using ImageMaster 2D Platinum 7.0. Protein spots were considered as candidates when the percent volume (\% volume) of consistent spots was significantly different between osteosarcoma and osteoblast cells (Student's t-test, $\mathrm{p}<0.05)$. For Tryptic In-gel digestion, the candidate spots were cut to small pieces and repeatedly incubated in $0.1 \mathrm{M}$ $\mathrm{NH}_{4} \mathrm{HCO}_{3}$ in $50 \%$ acetonitrite (ACN) to remove Coomassie dye. Reduction was performed by re-swelling the gel pieces in $50 \mu \mathrm{l}$ buffer solution and incubated at $60^{\circ} \mathrm{C}$ for $45 \mathrm{~min}$. After cooling, the excess liquid was removed and quickly replaced by the same volume of freshly prepared $100 \mathrm{mM}$ iodoacetamide in $0.1 \mathrm{M} \mathrm{NH}_{4} \mathrm{HCO}_{3}$ solution. The reaction was incubated in the dark at room temperature for $30 \mathrm{~min}$. The iodoacetamide solution was removed and the gel pieces were washed with $50 \% \mathrm{ACN}$ in water for $10 \mathrm{~min}$. Gel pieces were completely dried by centrifugation under vacuum. One spot of gel piece requires $30 \mu \mathrm{l}$ of trypsin digestion buffer. After incubating the reaction mixture at $37^{\circ} \mathrm{C}$ overnight, the digestion buffer was removed and saved in a new tube (peptide tube). The protein from the gel pieces were then extracted by adding $60 \mu \mathrm{l}$ of $2 \%$ freshly prepared trifluoroacetic acid and incubating for $30 \mathrm{~min}$ at $60^{\circ} \mathrm{C}$. The remaining solution was again saved in peptide tube (12). Extracted proteins within the peptide solution was finally pooled and dried by vacuum centrifugation. Samples were kept in $-20^{\circ} \mathrm{C}$ before being analyzed by LC-MS/MS.

LC-MS/MS analysis. Mass spectrometry, nanoflow liquid chromatography coupled with the AmaZon speed ion trap mass spectrometry (Bruker, MA, USA) was utilized to identify protein spots. A $75 \mu \mathrm{m}$ id $\mathrm{x} 100 \mathrm{~mm}$ C18 EASY-nLC ${ }^{\mathrm{TM}}$ column (Thermo Scientific, MA, USA) was used. Gradient separation was performed using $0.1 \%$ formic acid in water (solution A) and $0.1 \%$ formic acid in ACN (solution B) followed by MS/MS equipped with CaptiveSpray ${ }^{\mathrm{TM}}$ source. Parent mass peaks with ranges from 500 to $3,000 \mathrm{~m} / \mathrm{z}$ were picked out for MS/MS analysis. The collision energy was fixed at 3,000 V. The MS/MS data were processed using Burker compass 1.4 software. Peptides were searched with MASCOT search engine (http://www.matrixscience.com). The search parameters were set as follows: NCBInr 20130918 (October 2013; 32611672 sequences; 11345269536 residues) and SwissProt (October 2013; 540958 sequences; 192206270 residues) database, taxonomy Homo sapiens, enzyme set for trypsin, allowance of one missed cleavage, variable modifications were carbamidomethylation at cysteine residues and oxidation at methionine residues, peptide and fragment mass tolerance were 1.2 and $0.6 \mathrm{Da}$, respectively, the limit of peptide charges was $1+, 2+$, and $3+$. Significant hits were defined by the MASCOT probability analysis $(\mathrm{p}<0.05)$ with MASCOT scores $>48$.

Western blot analysis. Cells were lysed in RIPA lysis buffer (radioimmuno precipitation assay lysis). Extracted protein $(10 \mu \mathrm{g})$ was separated on a 10\% SDS-PAGE gel and then transferred to Immobilon-P polyvinylidene difluoride membranes (PVDF) (Millipore). Protein bands were visualized by chemi- luminescence using ECL-Advance Western Blotting Detection kit (GE Healthcare) (13). The antibody concentrations used for KSRP were 1:5,000, ab150393 (Abcam, UK), 1:1,000 for immunohistochemistry, $\beta$-actin 1:7,500, ab8227 (Abcam), goat anti-rabbit IgG H\&R 1:6,000 (Abcam).

Immunohistochemistry analysis. The sections, 3-micron formalin-fixed, paraffin-embedded tissue, were deparaffinized and hydrated. Heat mediated antigen retrieval was done in citrate buffer $\mathrm{pH} 6.0$ in a pressure cooker. Automated immunohistochemical staining was performed using a Ventana Benchmark XT automated stainer (Ventana Medical Systems, AZ, USA). The detection system was a Ventana Ultraview DAB detection kit (Ventana Medical Systems).

KSRP knock-down by small interference RNA (siRNA). Osteosarcoma cell line (MMNG-HOS) catalog no. CLS 300289 passage 24 and U2OS catalog no. CLS 300364 passage 24 were used as representative osteosarcoma cells. The siRNAs were diluted in serum-free OptiMEM media and transfected using Lipofectamine RNAiMAX reagent according to the manufacturer's instructions (Invitrogen, MA, USA). Short interference RNAs (siRNAs) against KSRP were synthesized using Ambion by Life Technologies (14). The sequences (sense/antisense) for the siRNAs were as follows: siRNA1 (5'-CAGGCUCAAUGAAUCGAAUtt-3'/5'-AUUCGAUUCAU UGAGCCUGct-3'); siRNA2 (5'-GGAUUCAGGCUGCAAA GUAtt-3'/5'-UACUUUGCAGCCUGAAUCCtg-3'). Cells were treated with KSRP siRNA (10 and $30 \mathrm{nM}$ ), non-targeting siRNA controls (10 and $30 \mathrm{nM})$ and transfection reagent only.

Wound healing assay. The MNNG-HOS and U2OS were transfected with $20 \mathrm{nM}$ KSRP siRNA and $20 \mathrm{nM}$ negative control siRNA for 48 and $72 \mathrm{~h}$. The cells were trypsinized and plated in 24-well plates at 90\% confluence and incubated for $18 \mathrm{~h}$. The monolayer cell culture was scratched with a $200-\mu \mathrm{l}$ yellow tip to create a wound line. The width of the wound gaps was measured using AxioVision Analytic Software and the percentage of migration ability was calculated. The formula was: $\%$ migration $=100 \%-[($ width at $\mathrm{X}$ hour $) /($ width at 0 hour $)$ $\mathrm{x} 100](15)$.

Tumor implantation in chick chorioallantoic membrane assay (CAM). Fertilized native crossbreed chicken eggs were obtained from the Department of Animal and Aquatic Science, Faculty of Agriculture, Chiang Mai University, and were incubated at $37.5^{\circ} \mathrm{C}$ and $60 \%$ relative humidity (16). On day 8 , the shells were cut at the blunt end of the egg, a $1 \times 1-\mathrm{cm}$ hole was created and the shell membrane was detached. A sterile plastic ring was placed on the CAM and $5 \times 10^{5}$ cells $/ 20 \mu \mathrm{l}$ of transfected cell solution was deposited after gentle laceration of the CAM surface (16). Only embryos surviving at day 15 were included in the analysis; tumors were collected. Tumor formation was observed and tumor size was estimated based on the tumor volume calculation $V=4 / 3 \pi r 3$, with $r=1 / 2$ square $\operatorname{root}(\mathrm{d} 1 \mathrm{x} \mathrm{d} 2)(16)$.

Statistical analysis. Gene expression levels, enzymatic activity levels, doubling time, protein intensity levels and tumor volume were compared between groups with the Mann-Whitney 
Table I. Characteristics of patients with osteosarcoma and non-cancer participants.

\begin{tabular}{|c|c|c|c|c|c|c|c|}
\hline $\begin{array}{l}\text { Case } \\
\text { ID }\end{array}$ & $\begin{array}{l}\text { Diagnosis } \\
\text { (site) }\end{array}$ & Gender & Age & $\begin{array}{l}\text { Tissue } \\
\text { from }\end{array}$ & $\begin{array}{l}\text { Enneking } \\
\text { stage }\end{array}$ & $\begin{array}{l}\% \text { Tumor } \\
\text { necrosis }^{\mathrm{a}}\end{array}$ & $\begin{array}{c}\text { Clinical status } \\
\text { (follow-up month) }\end{array}$ \\
\hline OS 1 & OS (femur) & $\mathrm{F}$ & 9 & Femur & IIB & 90 & Alive (36) \\
\hline OS 2 & OS (femur) & M & 21 & Femur & III & 15 & Alive $(28)^{\mathrm{b}}$ \\
\hline OS 3 & OS (femur) & $\mathrm{F}$ & 12 & Femur & IIB & 90 & Alive (36) \\
\hline OS 4 & OS (femur) & $\mathrm{F}$ & 5 & Femur & IIB & 10 & Dead $(15)^{c}$ \\
\hline OS 5 & OS (femur) & $\mathrm{F}$ & 15 & Femur & IIB & 90 & Alive (30) \\
\hline OS 6 & OS (tibia) & $\mathrm{F}$ & 16 & Tibia & IIB & 5 & Alive $(18)^{\mathrm{b}}$ \\
\hline OS 7 & OS (femur) & $\mathrm{F}$ & 18 & Femur & IIB & 10 & Alive (26) \\
\hline OB 1 & Fracture (femur) & $\mathrm{F}$ & 23 & Iliac crest & - & - & Alive (36) \\
\hline OB 2 & Fracture (femur) & M & 24 & Iliac crest & - & - & Alive (36) \\
\hline OB 3 & Fracture (tibia) & M & 35 & Iliac crest & - & - & Alive (30) \\
\hline OB 4 & $\begin{array}{l}\text { Chondroblastoma } \\
\text { (humerus) }\end{array}$ & $\mathrm{F}$ & 11 & Iliac crest & - & - & Alive (30) \\
\hline OB 5 & Bone cyst (femur) & M & 12 & Iliac crest & - & - & Alive (30) \\
\hline OB 6 & Fracture (tibia) & $\mathrm{F}$ & 17 & Iliac crest & - & - & Alive (28) \\
\hline OB 7 & Scoliosis (spine) & $\mathrm{F}$ & 15 & Iliac crest & - & - & Alive (26) \\
\hline
\end{tabular}

OS, osteosarcoma (conventional subtype); OB, osteoblast. ${ }^{\mathrm{a}} \%$ Tumor necrosis after chemotherapy. ${ }^{\mathrm{b} D i s e a s e}$ recurrence or lung metastasis at last follow-up. ${ }^{\mathrm{C}}$ Period of overall survival.

U test or the Kruskal-Wallis test. The statistical significance was defined as $\mathrm{p}<0.05$.

\section{Results}

Osteosarcoma and osteoblast characterization. The demographic characterizations and survival rate of patients with osteosarcoma $(n=7)$ and participants $(n=7)$ are presented in Table I. The average doubling time of osteosarcoma and osteoblast cells was $75.6 \pm 6.0$ and $148.6 \pm 26.0 \mathrm{~h}$, respectively $(\mathrm{p}<0.05)$. Both types of primary cells expressed osteogenic markers (collagen type-I, bonesialoprotein and osteonectin), but the osteoblasts were expressed at higher levels than osteosarcomas. On the other hand, collagen type-X and MMP-9 were significantly upregulated in the osteosarcomas (data not shown). The high activity of MMP-9 in osteosarcoma cells was confirmed by zymographic assay (data not shown). Osteoblasts showed more mineralization ability than osteosarcoma cells on days 21 and 28 (data not shown). When cells were activated with osteogenic media, alkaline phosphatase activity was significantly increased in osteoblast cells compared to osteosarcoma cells (data not shown).

Proteomic analysis and candidate protein selection. The representative gels from osteosarcoma and osteoblast cells are shown in Fig. 1A. The average number of protein spots from osteosarcoma and osteoblast cells was $348 \pm 30$ and $415 \pm 74$, respectively. There were $257 \pm 62$ matching spots from all 49 matched sets, but only 33 spots had consistent presentation of either up- or downregulation. Thirty-three spots were categorized as follows; $29 \%$ of all consistent proteins involved in ribonucleic metabolism, $14 \%$ were cytoskeletal and cytoskeletal related proteins, $14 \%$ involved in redox reaction related proteins, $11 \%$ involved in cellular metabolism, $6 \%$ were protease proteins, and $26 \%$ were either signal transduction related proteins or other proteins. There were four statistically significant upregulated proteins: KH-type splicing regulatory protein (KSRP), endoplasmic reticulum resident protein 29 (ERP29), thioredoxin-dependent peroxidase reductase (PRDX3), and transgelin (TAGL). There were three statistically significant downregulated proteins: protein disulfide-isomerase A3 (PDIA3), actin, cytoplasmic1 (ACTB), and Annexin A1 (ANXA1) (Fig. 1B). The details of protein identification from LC-MS/MS are shown in Table II.

Levels of KSRP expression in samples, cell lines, and other cases of the experimental group. KH-type splicing regulatory protein (far upstream element-binding protein 2: FUBP2) was the protein of interest, and was selected for further detailed exploration. Western blot analysis was performed in both pooled samples and crude protein extracted from individual samples. Relatively high regulation was indicated by the intensity of the western blots as shown in Fig. 2A. KSRP was also observed in MNNG-HOS and U2OS, human osteosarcoma cell lines. KSRP expression in primary biopsies of 12 representative osteosarcoma cases, the separate cases from the proteomics study, are demonstrated by immunohistochemistry staining in Fig. 2B. All cases revealed diffuse and strong nuclear staining in tumor cells.

KSRP silencing decreases migration ability, and proliferation rate of osteosarcoma cells. The KSRP silencing conditions were optimized at 24, 48, 72 and $96 \mathrm{~h}$. Both siRNA-1 and siRNA-2 compromised KSRP expression from $24 \mathrm{~h}$ comparing to non-sense from both cell lines and persisted $>96 \mathrm{~h}$ (Fig. 3). The KSRP silencing at 48 and $72 \mathrm{~h}$ was subjected to wound 


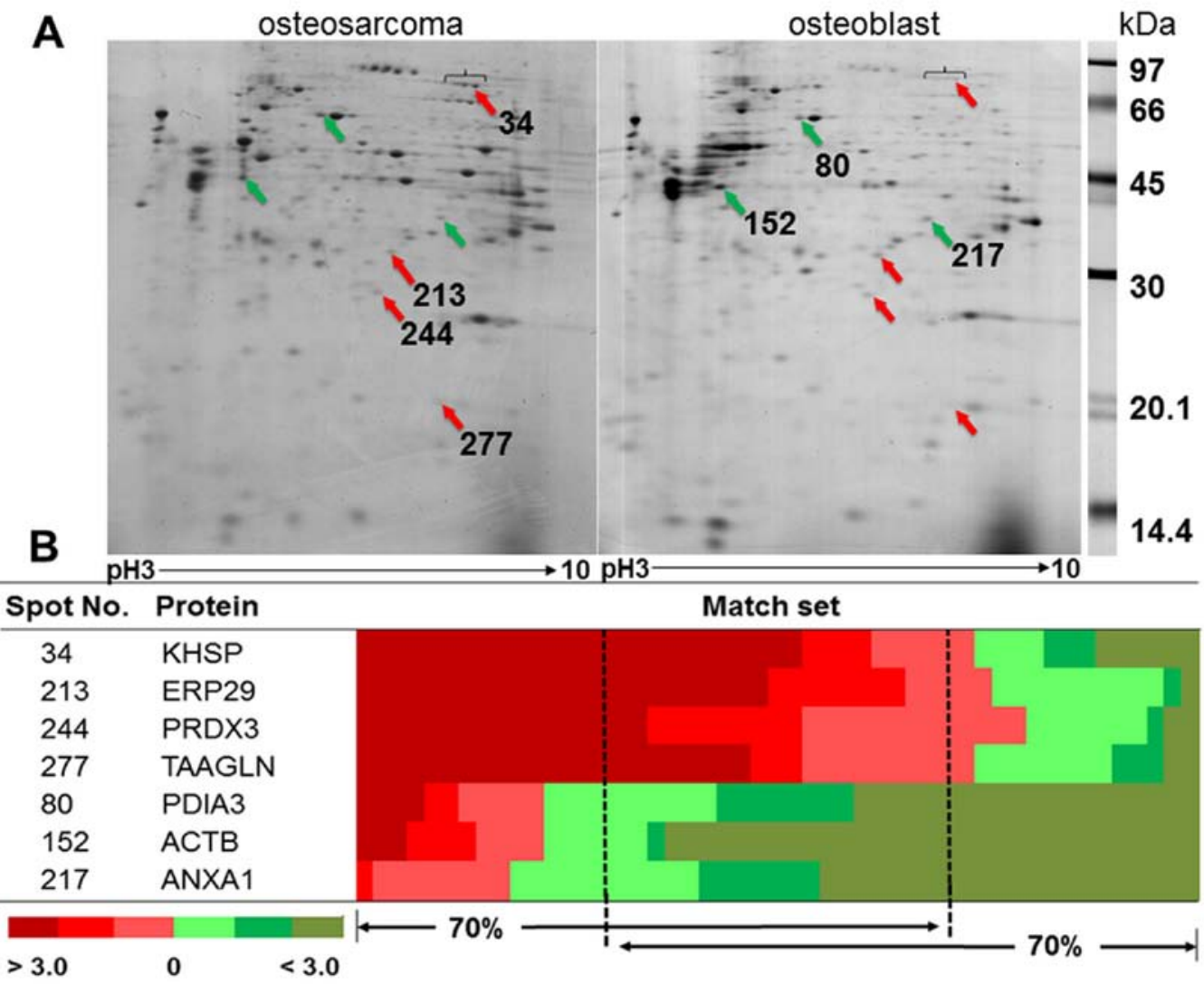

Figure 1. Representative 2D-PAGE of osteosarcoma and osteoblast. (A) Red arrows show spots significantly upregulated in osteosarcomas; green arrows show spots significantly upregulated in osteoblasts. (B) Heat map shows fold changes of $\%$ volume of protein spots between osteosarcoma and osteoblast in each matched set.

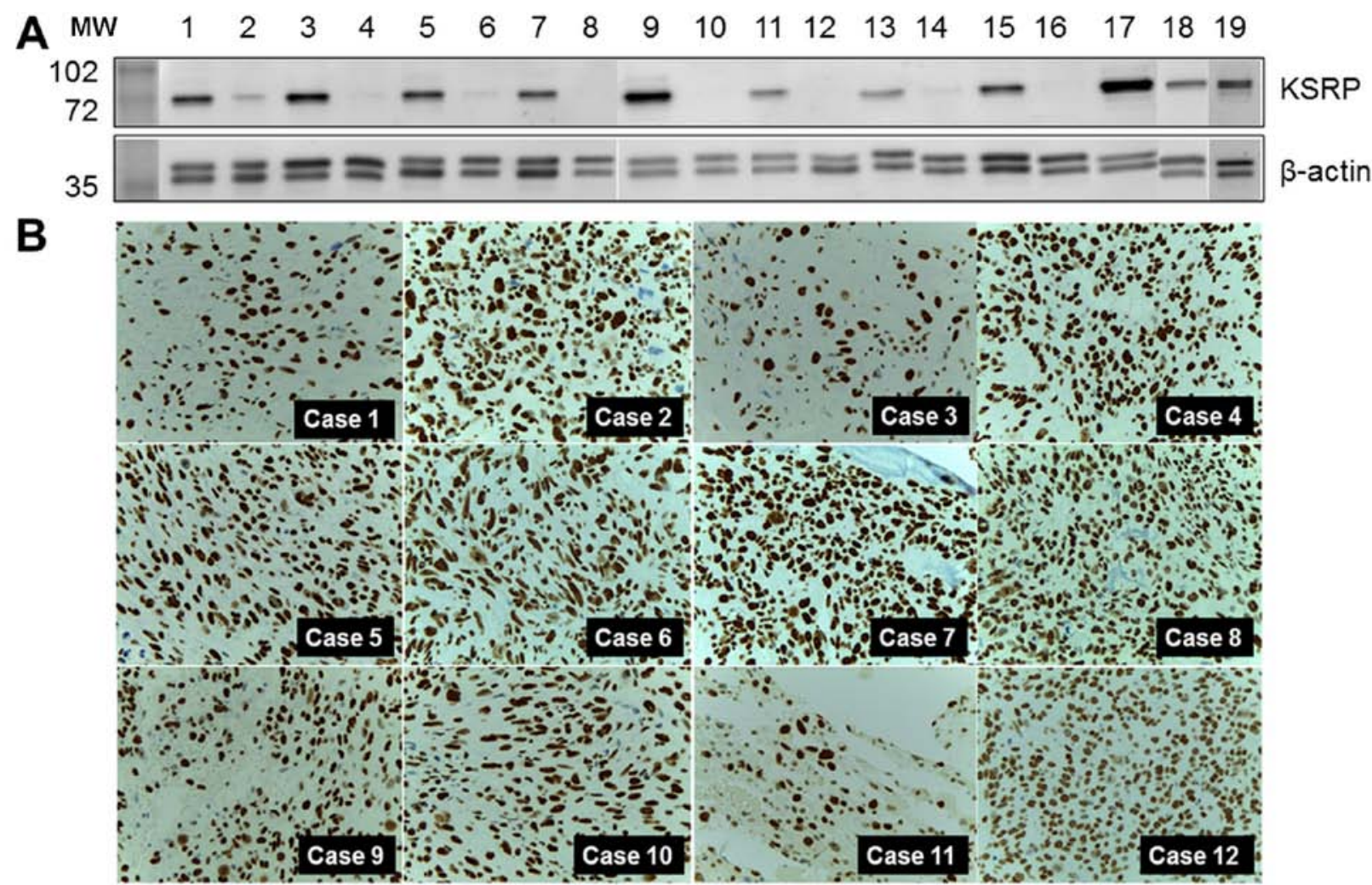

Figure 2. (A) KSRP expression levels in experimental samples (1, pooled sample of osteosarcoma; 2, pool sample of osteoblasts; 3-15 (odd number), individual osteosarcoma cases; 2-16 (even number), individual osteoblast cases; 17, MNNG-HOS; 18, U2OS; 19, HeLa cells as the positive control). (B) KSRP expression in 12 representative biopsy samples of osteosarcoma cases in the separate group. 
Table II. Summary of significant altered proteins in primary osteosarcoma cells identified by LC-MS/MS.

\begin{tabular}{|c|c|c|c|c|c|c|c|}
\hline & & & & & & & $\begin{array}{l}\% \text { Volume intensity } \\
\quad(\text { mean } \pm \mathrm{SD})^{\mathrm{d}}\end{array}$ \\
\hline ID & $\begin{array}{c}\text { Accession } \\
\text { no. }^{\text {a }}\end{array}$ & Name & Gene & $\begin{array}{c}\mathrm{MW} / \mathrm{pI} \\
(\mathrm{kDa} / \mathrm{pI})^{\mathrm{b}}\end{array}$ & $\begin{array}{l}\text { MASCOT } \\
\text { score }\end{array}$ & $\begin{array}{c}\text { Peptide } \\
\text { match }^{\mathrm{c}} \% \\
\text { coverage }\end{array}$ & Osteosarcoma Osteoblast \\
\hline
\end{tabular}

Upregulated protein

34

213

244

277

Downregulated

protein

80

152

217

17

\begin{tabular}{|c|c|}
\hline gil2055427 & $\begin{array}{l}\text { KH-type splicing } \\
\text { regulatory protein }\end{array}$ \\
\hline gil5803013 & $\begin{array}{l}\text { Endoplasmic reticulu } \\
\text { resident protein } 29\end{array}$ \\
\hline gil5802974 & $\begin{array}{l}\text { Thioredoxin-depender } \\
\text { peroxide reductase, } \\
\text { mitochondrial }\end{array}$ \\
\hline
\end{tabular}

TAGLN 22.6/8.87

PRDX3 27.7/7.67
255

$6 / 7$

$0.156 \pm 0.11 \quad 0.049 \pm 0.03$

270

$5 / 18$

$0.411 \pm 0.49 \quad 0.131 \pm 0.02$

239

$5 / 18$

$0.217 \pm 0.09 \quad 0.110 \pm 0.06$

97

197

$4 / 21$

$0.662 \pm 0.59 \quad 0.307 \pm 0.24$

\author{
TAGLN 22.6/8.87
}

$\begin{array}{llllll}\text { PDIA3 } & 56.7 / 5.98 & 279 & 6 / 10 & 0.178 \pm 0.14 & 0.332 \pm 0.16 \\ & & & & & \\ \text { ACTB } & 41.71 / 5.29 & 160 & 7 / 21 & 0.992 \pm 1.07 & 2.715 \pm 1.98 \\ \text { ANXA1 } & 38.7 / 6.57 & 359 & 7 / 19 & 0.113 \pm 0.05 & 0.264 \pm 0.12\end{array}$

${ }^{a}$ Database accession numbers are from NCBInr. ${ }^{b}$ Theoretical molecular weight and pI from MASCOT database. ${ }^{\mathrm{c}}$ Number of unique peptides identified by MS/MS. ${ }^{\mathrm{d}} \mathrm{All}$ spots in this column are statistically significant at $\mathrm{p}<0.001$.

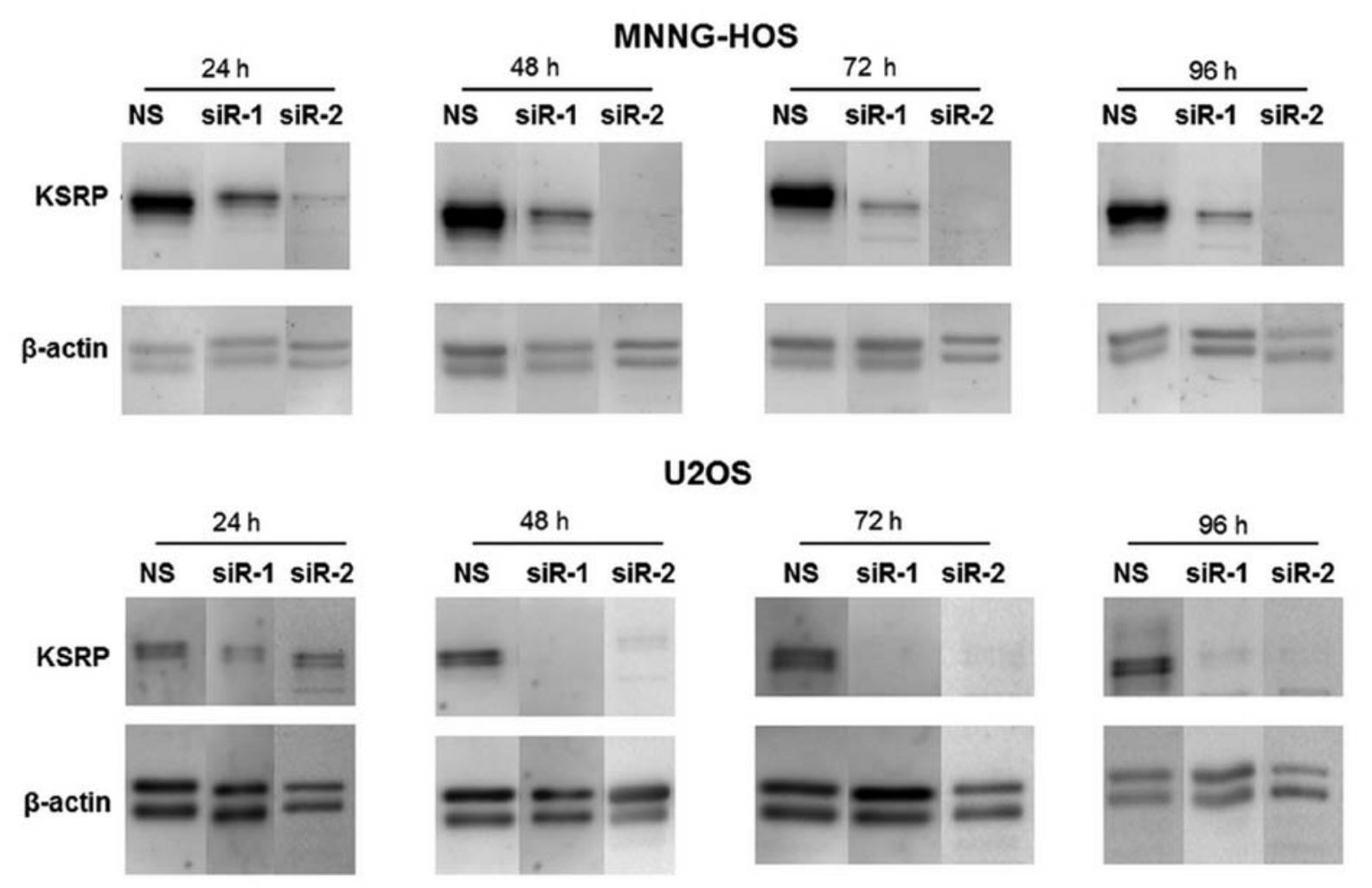

Figure 3. Western blot analysis show the intensity of KSRP protein after knocked down with siRNA-1 (siR-1) and siRNA-2 (siR-2) comparing with non-sense control (NS) at various incubation times at 24, 48, 72 and $96 \mathrm{~h}$ in MNNG-HOS and U2OS. 

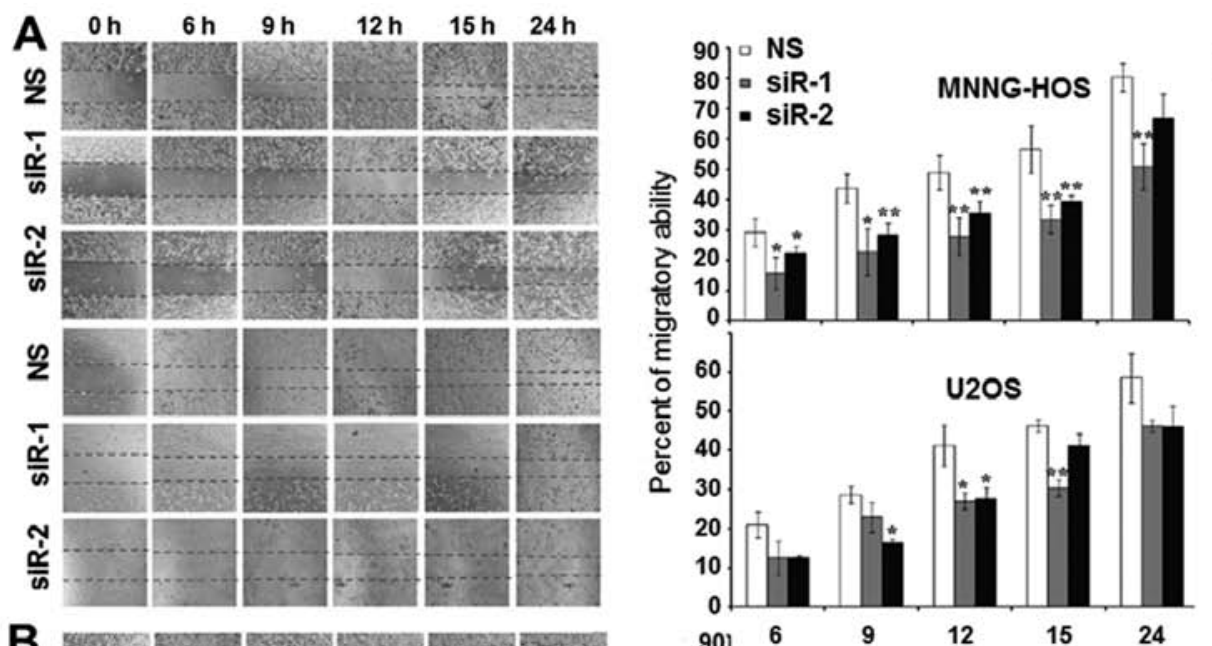

\section{Cell number $\times 10^{3}$}
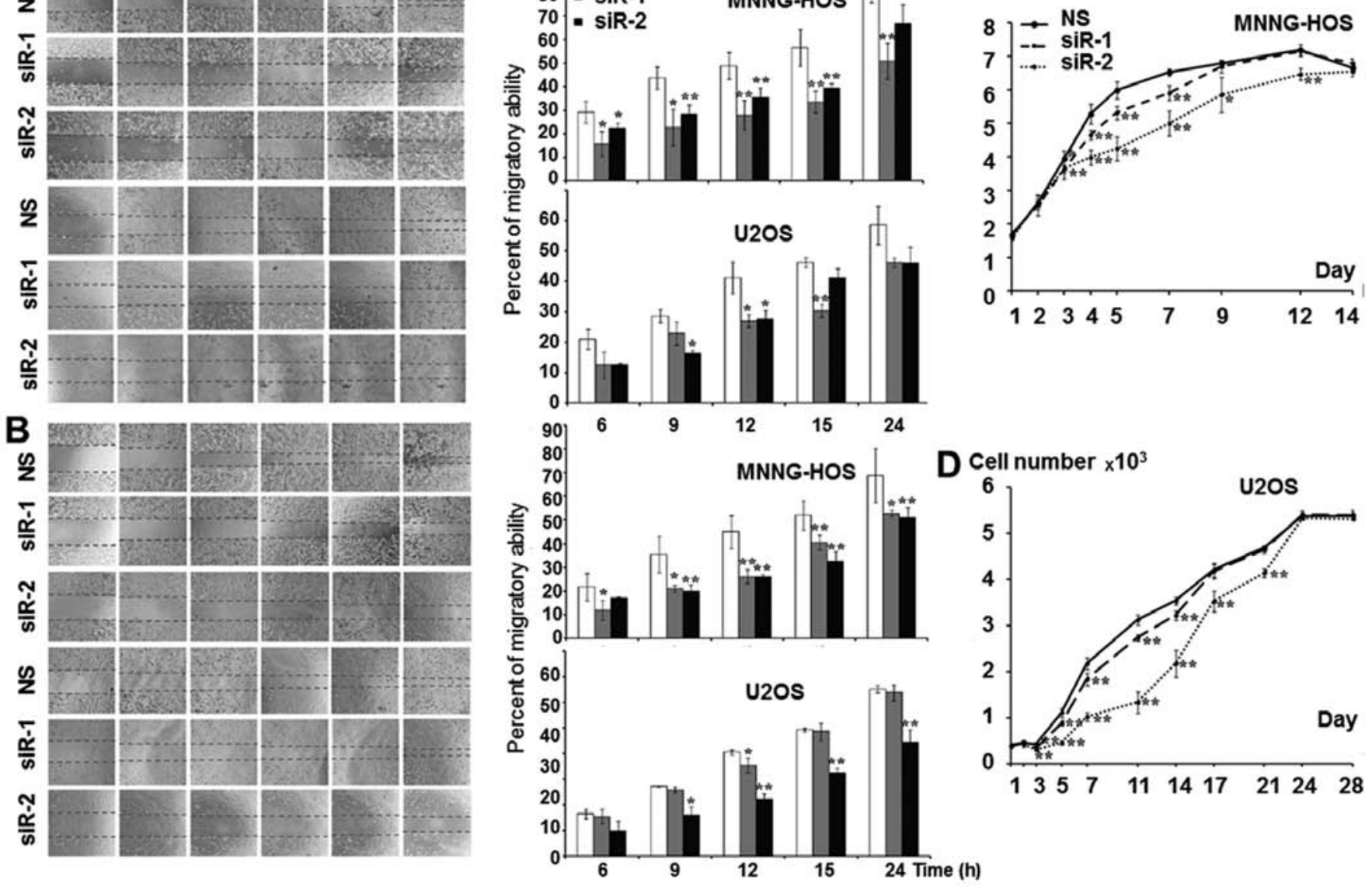

Figure 4. Significantly decreased migratory behavior of osteosarcoma cell lines after KSRP knock-down by siRNA-1 (siR-1) and si-RNA2 (siR-2) compared with non-sense (NS) siRNA as a control (A) at $48 \mathrm{~h}$ and (B) at $72 \mathrm{~h}$. (C) Cell growth curve showing significantly decreased proliferative ability of osteosarcoma cell lines after KSRP knock-down.

Table III. The comparative data of implanted tumor in CAM model.

\begin{tabular}{lccc}
\hline & Non-sense & siRNA-1 & siRNA-2 \\
\hline Number of implantation & 15 & 15 & 15 \\
Embryo survive & 14 & 10 & 12 \\
Tumor forming: membrane & $13: 1$ & $7: 3$ & $2: 10$ \\
Tumor forming (\%) $^{\mathrm{a}}$ & 93 & 70 & 17 \\
Ten selected presentation (membrane) $^{\mathrm{b}}$ & 10 & $7(3)$ & $2(8)$ \\
Mean tumor volume \pm SD (ml) & $1.14(0.65)$ & $0.36(0.40)$ & $0.15(0.34)$ \\
p-value & & 0.005 & $<0.001$ \\
\hline
\end{tabular}

${ }^{a}$ Tumor forming, tumor forming/survive embryo. ${ }^{\mathrm{b}}$ Selected from the largest tumor of the series, membrane determined as zero volume.

healing assay. KSRP silencing decreased the migratory rate of both cell lines. Silencing by siRNA-2 presented a stronger inhibitory effect in both MNNG-HOS and U2OS than siRNA-1 as shown in Fig. 4A and B with both 48 and $72 \mathrm{~h}$ of incubation. The proliferative rates were significantly reduced in both cell lines and both types of siRNA. Silencing by siRNA-2 presented a stronger proliferative inhibition in both MNNG-HOS and U2OS compared to siRNA-1 as shown in Fig. $4 \mathrm{C}$ and $\mathrm{D}$, respectively.
KSRP silencing impairs implant and growth ability of osteosarcoma cells in CAM model. MNNG-HOS cell lines exhibited good ability for successful implantation in the CAM model (16). This study used MNNG-HOS to represent osteosarcoma growth in the CAM model. KSRP silencing with siRNA-1 and siRNA-2 decreased rates of tumor implantation 70 and 25\%, respectively, shown in Table III. Mass-forming tumors and non-mass-forming tumors (membrane) are shown in Fig. 5A. The average tumor size of the non-sense group 


\section{A Non-sense}

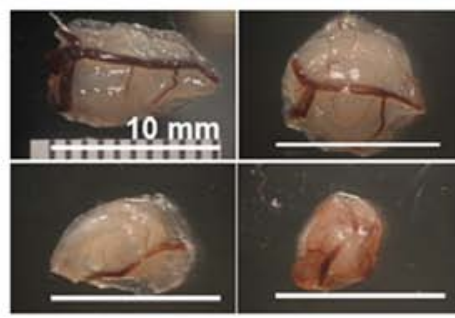

SiRNA-1
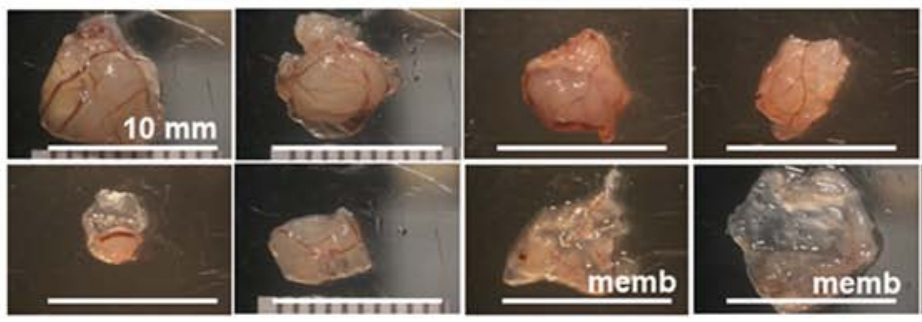

SiRNA-2
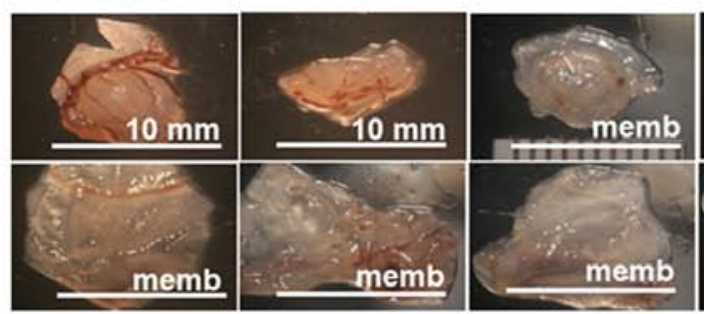
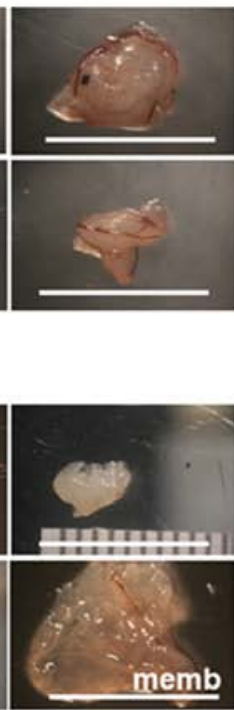

B

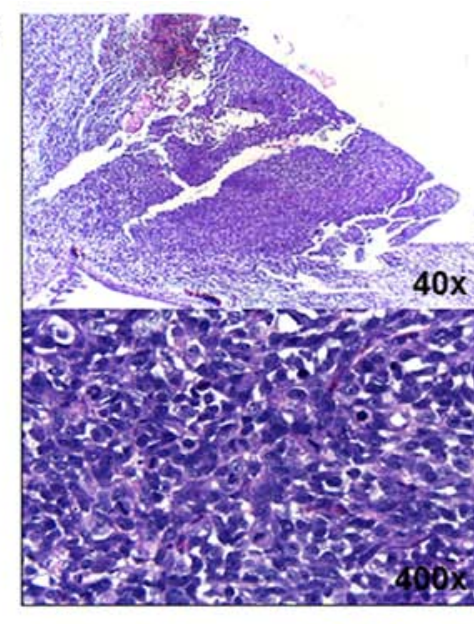

C

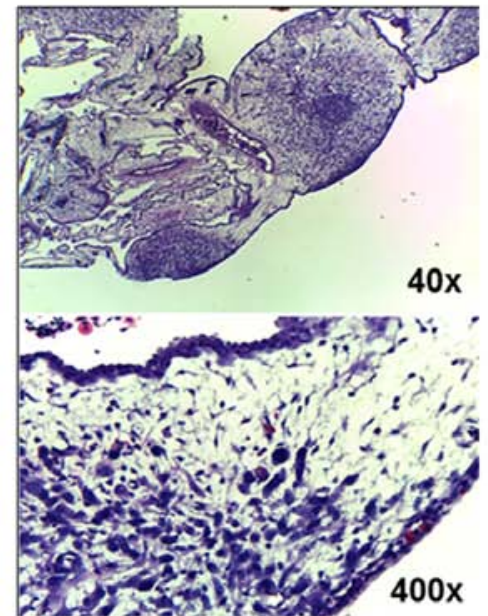

Figure 5. (A) The ten largest implanted tumors of non-sense, siRNA-1, and siRNA-2 of KSRP knocked down MNNG-HOS in CAM assay. (B) The representative histology of mass-forming tumors was observed as a proliferative nodular architecture with high cellularity, dense deep blue colony, embedded in chorioallantoic membrane (H\&E, x40). Plump spindle malignant cells which are anisonucleosis, nuclear pleomorphism, hyperchromatin patterns, and prominent nucleoli supplied by chick vasculature. Mitotic figures were frequently observed (H\&E, x400). (C) The representative histology of non-massforming tumor (membrane) showed small loose colonies of tumors embedded in chorioallantoic membrane (H\&E, $\mathrm{x} 40$ ), and hypocellular cancer cells loosely in extracellular matrix within edematous chick membrane (H\&E, $\mathrm{x} 400)$.

was significantly larger, and more number of mass-forming tumors than that presented by KSRP silencing with siRNA-1 and siRNA-2, respectively. The representative histology of mass-forming tumor showed a dense population of cancer cells (Fig. 5B) and the histology of non-mass-forming tumors showed small loose colonies of tumors embedded in chorioallantoic membrane (Fig. 5C).

\section{Discussion}

There have been few studies of bone analysis using proteomic technologies comparing other types of tissues because the preparation of samples with different physical properties was limited, thus restricting the opportunity for comparison. There are thirty-one studies including the keywords 'osteosarcoma' 'human' and 'proteomics' which were listed on the PubMed database until the year 2015. Twenty-one studies were conducted in human osteosarcoma cell lines, four were investigated in serum or plasma from patients, and six were based on patient tissues. Of those six, one compared proteomics of formalin-fixed paraffin-embedded tissues between osteosarcoma and desmoid tumors (benign fibrous tumors) (17). Another study compared the proteomic profiles of osteosarcoma tissue and benign bone tumors (18). Three of six research efforts studied biopsy samples from both good and poor response chemotherapy cases (19-21). Peroxiredoxin 2 (PRDX2) was expressed at higher levels in the poor responders and siRNA-induced silencing of PRDX2 resulted in a decrease of proliferation, invasion and migration in osteosarcoma cells $(20,21)$. Heterogeneous tissue of sample and control, for which it is difficult to identify an exact zone of pathogenesis, might alter the protein outcome during the analysis process. Folio et al used a different approach, extracting the primary cells from a biopsy sample of osteosarcoma tissue and osteoblast cells from cancellous bone from patients. Crystallin $\alpha / \beta$ and ezrin were selected for study in greater detail (22). Ezrin has been widely studied for its role of metastasis behavior in osteosarcoma, and is becoming a potential target for metastasis control (23).

Significant upregulation of KH type splicing regulatory protein (KSRP or FUBP2) was found in proteomics study of our experiment, and the strong evidence of KSRP existence was demonstrated by western blot analysis of experimental samples, and immunohistochemistry from primary biopsy sample of osteosarcoma tissue ( $n=12$ cases) out of the 
experimental group. Previous studies showed important roles of KSRP in pathogenesis of some cancers including hepatocellular carcinoma (HCC), colon cancer, and some hematologic malignancies upon diverse molecular mechanisms. Upregulated KSRP was found in HCC comparing to normal liver tissue via 2D-DIGE profiling (24). Overexpression related to proliferation and dissemination behavior of $\mathrm{HCC}$, and correlated with a poor survival rate in patients (25). Overexpression of KSRP was able to inactivate $\beta$-catenin/ Lymphoid-enhancer factor/T-cell factor(Lef/Tcf)-sensitive transcription in colon carcinoma (26). KSRP is involved in maturation of several miRNAs which were dysregulated in leukemia and lymphoma (27).

KSRP is a member of the far upstream element (FUSE) binding protein family. The far upstream binding element is an AT rich DNA element located $1.7 \mathrm{~kb}$ upstream of the $c-m y c$ oncogene promoter. Three members of the family include the proteins FUBP1, FUBP2, and FUBP3, all of which are able to bind to the FUSE and to upregulate the expression of the $c$-myc $(28,29)$. It is possible that KSRP is involved in pathogenesis of osteosarcoma through c-Myc regulation. c-Myc amplification was also present in up to $78 \%$ of cases in later studies which used conventional cytogenetic and comparative genomic hybridization (30). Using immunohistochemistry, expression of c-Myc was observed in up to $85.7 \%$ of osteosarcoma tissue samples and was significantly correlated with the survival time (31). A recent study using a mouse model suggested that c-Myc amplification was the key regulator and was sufficient to drive both bone marrow mesenchymal stem cells and lineage-committed immature osteoblasts into becoming osteosarcoma (32).

KSRP has other roles in post-translational regulation by controlling mRNA level and miRNA maturation process. KSRP is one of the AU-rich element-binding proteins (AREBP) controlling the target mRNA level. The stability of $\beta$-catenin mRNA level was maintained through phosphorylation of KSRP activated by PI3-kinase/AKT signaling (33). Suppression of KSRP level increased 5-fold accumulation of $\beta$-catenin, and provoked activation of $\beta$-catenin transcription targets. On the other hand, overexpression of KSRP level attenuated Wnt3a-induced $\beta$-catenin accumulation (34). The inactivation of the $\mathrm{Wnt} / \beta$-catenin pathway was also found to relate with tumorigenesis of osteosarcoma (35).

KSRP controls the maturation of miRNA by interacting with the terminal loop of miRNA precursors, and it is also able to interact with Drosha and Dicer in the miRNA maturation process (36). Therefore, KSRP presents its diversity function involving many biological processes including the stem cell differentiation and cancer pathogenesis. KSRP has demonstrated a role in controlling mesenchymal stem cells during the cell fate differentiation between myoblast and osteoblast differentiation. The presence of KSRP plays a critical role in blocking mesenchymal stem cell differentiation toward osteoblast by enhancing the BMP2-dependent myogenic miRNA maturation process (37).

KSRP controls maturation of the Let-7 miRNA family which is known as a tumor suppressive miRNA (38). KSRP knock-down limited Let-7 miRNA maturation and increased mRNA levels of Let-7 targets including c-Myc (39). Decreasing maturation of Let-7a miRNA after KSRP knock- down was also demonstrated in the U2OS, osteosarcoma cell line, and resulted in increased cell proliferation (36). On the other hand, overexpression of Lin-28 plays an opposite role to the KSRP controlling levels of Let-7 maturation. Lin-28 is able to bind to Let-7 miRNA at the terminal loop, at the same site of KSRP, and leading to suppression of Let-7 maturation (40). There is still only limited data on the indirect regulation control between KSRP and Lin-28 and Let-7 family maturation process for the pathogenesis of osteosarcoma.

This study has not covered in detail the intensities of signals from both promoter control of c-Myc and other mechanisms, downstream effects, or crosstalk with other related proteins. However, results of our study supported that KSRP would be one of the candidate proteins for osteosarcoma control. KSRP and related cascades also have been studied as potential new targets for cancer treatment. Curcumin analogue (GO-Y086) is able to bind with nuclear protein KSRP by covalent modification and markedly suppresses c-Myc protein expression. GO-Y086 has been studied for the control of c-Myc expression in colon cancer cell lines (HCT116) (41).

In conclusion, our study supports overexpression of KSRP to be involved in pathogenesis of osteosarcoma and related to the aggressive phenotypes of osteosarcoma cells. KSRP might be a potential target for further studies at a higher level for disease control. Up- and down-stream regulation of KSRP overexpression are appropriate for further exploration to identify more potential biomarkers and therapeutic targets for osteosarcoma.

\section{Acknowledgements}

This study received funding from the National Science and Technology Development Agency (NSTDA), code P-12-01469, and the Faculty of Medicine, Chiang Mai University. Additional support was provided by the Excellence Center in Osteology Research and Training Center (ORTC), Chiang Mai University, and The Thailand National Research University (NRU) Fund. The authors would also like to express their sincere thanks to Dr G. Lamar Robert for editing the English manuscript.

\section{References}

1. Mirabello L, Troisi RJ and Savage SA: International osteosarcoma incidence patterns in children and adolescents, middle ages and elderly persons. Int J Cancer 125: 229-234, 2009.

2. Allison DC, Carney SC, Ahlmann ER, Hendifar A, Chawla S, Fedenko A, Angeles C and Menendez LR: A meta-analysis of osteosarcoma outcomes in the modern medical era. Sarcoma 2012: 704872, 2012.

3. Gelberg KH, Fitzgerald EF, Hwang S and Dubrow R: Growth and development and other risk factors for osteosarcoma in children and young adults. Int J Epidemiol 26: 272-278, 1997.

4. Ottaviani $\mathrm{G}$ and Jaffe $\mathrm{N}$ : The etiology of osteosarcoma. Cancer Treat Res 152: 15-32, 2009.

5. Zhou W, Hao M, Du X, Chen K, Wang G and Yang J: Advances in targeted therapy for osteosarcoma. Discov Med 17: 301-307, 2014.

6. Jonsson KB, Frost A, Nilsson O, Ljunghall S and Ljunggren $\mathrm{O}$ : Three isolation techniques for primary culture of human osteoblast-like cells: A comparison. Acta Orthop Scand 70: 365-373, 1999.

7. Pautke C, Schieker M, Tischer T, Kolk A, Neth P, Mutschler W and Milz S: Characterization of osteosarcoma cell lines MG-63, Saos-2 and U-2 OS in comparison to human osteoblasts. Anticancer Res 24: 3743-3748, 2004. 
8. Alameh M, Jean M,Dejesus D, Buschmann MD and Merzouki A Chitosanase-based method for RNA isolation from cells transfected with chitosan/siRNA nanocomplexes for real-time RT-PCR in gene silencing. Int J Nanomed 5: 473-481, 2010.

9. Martins AM, Pham QP, Malafaya PB, Sousa RA, Gomes ME, Raphael RM, Kasper FK, Reis RL and Mikos AG: The role of lipase and alpha-amylase in the degradation of starch/ poly(epsilon-caprolactone) fiber meshes and the osteogenic differentiation of cultured marrow stromal cells. Tissue Eng Part A 15: 295-305, 2009.

10. Gregory CA, Gunn WG, Peister A and Prockop DJ: An Alizarin red-based assay of mineralization by adherent cells in culture: Comparison with cetylpyridinium chloride extraction. Anal Biochem 329: 77-84, 2004

11. Kleiner DE and Stetler-Stevenson WG: Quantitative zymography: Detection of picogram quantities of gelatinases. Anal Biochem 218: 325-329, 1994.

12. Pruksakorn D, Lirdprapamongkol K, Chokchaichamnankit D, Subhasitanont P, Chiablaem K, Svasti J and Srisomsap C: Metabolic alteration of HepG2 in scaffold-based 3-D culture: Proteomic approach. Proteomics 10: 3896-3904, 2010.

13. Bolt MW and Mahoney PA: High-efficiency blotting of proteins of diverse sizes following sodium dodecyl sulfate-polyacrylamide gel electrophoresis. Anal Biochem 247: 185-192, 1997.

14. Weil D, Garçon L, Harper M, Duménil D, Dautry F and Kress M: Targeting the kinesin Eg5 to monitor siRNA transfection in mammalian cells. Biotechniques 33: 1244-1248, 2002.

15. Ridley AJ, Schwartz MA, Burridge K, Firtel RA, Ginsberg MH, Borisy G, Parsons JT and Horwitz AR: Cell migration: Integrating signals from front to back. Science 302: 1704-1709, 2003.

16. Balke M, Neumann A, Kersting C, Agelopoulos K, Gebert C, Gosheger G, Buerger H and Hagedorn M: Morphologic characterization of osteosarcoma growth on the chick chorioallantoic membrane. BMC Res Notes 3: 58, 2010

17. Rao UN, Hood BL, Jones-Laughner JM, Sun M and Conrads TP Distinct profiles of oxidative stress-related and matrix proteins in adult bone and soft tissue osteosarcoma and desmoid tumors: A proteomics study. Hum Pathol 44: 725-733, 2013

18. Li Y, Liang Q, Wen YQ, Chen LL, Wang LT, Liu YL, Luo CQ, Liang HZ, Li MT and Li Z: Comparative proteomics analysis of human osteosarcomas and benign tumor of bone. Cancer Genet Cytogenet 198: 97-106, 2010

19. Kawai A, Kondo T, Suehara Y, Kikuta K and Hirohashi S: Global protein-expression analysis of bone and soft tissue sarcomas. Clin Orthop Relat Res 466: 2099-2106, 2008.

20. Kikuta K, Tochigi N, Saito S, Shimoda T, Morioka H, Toyama Y, Hosono A, Suehara Y, Beppu Y, Kawai A, et al: Peroxiredoxin 2 as a chemotherapy responsiveness biomarker candidate in osteosarcoma revealed by proteomics. Proteomics Clin Appl 4: $560-567,2010$

21. Kubota D, Mukaihara K, Yoshida A, Tsuda H, Kawai A and Kondo T: Proteomics study of open biopsy samples identifies peroxiredoxin 2 as a predictive biomarker of response to induction chemotherapy in osteosarcoma. J Proteomics 91: 393-404, 2013

22. Folio C, Mora MI, Zalacain M, Corrales FJ, Segura V, Sierrasesúmaga L, Toledo G, San-Julián M and Patiño-García A: Proteomic analysis of chemonaive pediatric osteosarcomas and corresponding normal bone reveals multiple altered molecular targets. J Proteome Res 8: 3882-3888, 2009.

23. Ren $L$ and Khanna C: Role of ezrin in osteosarcoma metastasis Adv Exp Med Biol 804: 181-201, 2014.

24. Zubaidah RM, Tan GS, Tan SB, Lim SG, Lin Q and Chung MC: 2-D DIGE profiling of hepatocellular carcinoma tissues identified isoforms of far upstream binding protein (FUBP) as novel candidates in liver carcinogenesis. Proteomics 8: 5086-5096, 2008.

25. Malz M, Weber A, Singer S, Riehmer V, Bissinger M, Riener MO, Longerich T, Soll C, Vogel A, Angel P, et al: Overexpression of far upstream element binding proteins: A mechanism regulating proliferation and migration in liver cancer cells. Hepatology 50: $1130-1139,2009$
26. Sinner D, Kordich JJ, Spence JR, Opoka R, Rankin S, Lin SC, Jonatan D, Zorn AM and Wells JM: Sox 17 and Sox 4 differentially regulate beta-catenin/T-cell factor activity and proliferation of colon carcinoma cells. Mol Cell Biol 27: 7802-7815, 2007.

27. Baou M, Norton JD and Murphy JJ: AU-rich RNA binding proteins in hematopoiesis and leukemogenesis. Blood 118: 5732-5740, 2011.

28. Davis-Smyth T, Duncan RC, Zheng T, Michelotti G and Levens D: The far upstream element-binding proteins comprise an ancient family of single-strand DNA-binding transactivators. J Biol Chem 271: 31679-31687, 1996.

29. Liu J, Kouzine F, Nie Z, Chung HJ, Elisha-Feil Z, Weber A, Zhao K and Levens D: The FUSE/FBP/FIR/TFIIH system is a molecular machine programming a pulse of c-myc expression. EMBO J 25: 2119-2130, 2006.

30. Squire JA, Pei J, Marrano P, Beheshti B, Bayani J, Lim G, Moldovan L and Zielenska M: High-resolution mapping of amplifications and deletions in pediatric osteosarcoma by use of CGH analysis of cDNA microarrays. Genes Chromosomes Cancer 38: 215-225, 2003

31. Wu X, Cai ZD, Lou LM and Zhu YB: Expressions of p53, c-MYC, BCL-2 and apoptotic index in human osteosarcoma and their correlations with prognosis of patients. Cancer Epidemiol 36: 212-216, 2012

32. Shimizu T, Ishikawa T, Sugihara E, Kuninaka S, Miyamoto T, Mabuchi Y, Matsuzaki Y, Tsunoda T, Miya F, Morioka H, et al: c-MYC overexpression with loss of Ink4a/Arf transforms bone marrow stromal cells into osteosarcoma accompanied by loss of adipogenesis. Oncogene 29: 5687-5699, 2010

33. Gherzi R, Trabucchi M, Ponassi M, Ruggiero T, Corte G, Moroni C, Chen CY, Khabar KS, Andersen JS and Briata P: The RNA-binding protein KSRP promotes decay of beta-catenin mRNA and is inactivated by PI3K-AKT signaling. PLoS Biol 5: e5, 2006.

34. Bikkavilli RK and Malbon CC: Dishevelled-KSRP complex regulates Wnt signaling through post-transcriptional stabilization of beta-catenin mRNA. J Cell Sci 123: 1352-1362, 2010.

35. Cai Y, Mohseny AB, Karperien M, Hogendoorn PC, Zhou G and Cleton-Jansen AM: Inactive Wnt/beta-catenin pathway in conventional high-grade osteosarcoma. J Pathol 220: 24-33, 2010.

36. Trabucchi M, Briata $P$, Garcia-Mayoral M, Haase AD, Filipowicz W, Ramos A, Gherzi R and Rosenfeld MG: The RNA-binding protein KSRP promotes the biogenesis of a subset of microRNAs. Nature 459: 1010-1014, 2009.

37. Pasero M, Giovarelli M, Bucci G, Gherzi R and Briata P: Bone morphogenetic protein/SMAD signaling orients cell fate decision by impairing KSRP-dependent microRNA maturation. Cell Rep 2: 1159-1168, 2012.

38. Nicastro G, García-Mayoral MF, Hollingworth D, Kelly G, Martin SR, Briata P, Gherzi R and Ramos A: Noncanonical G recognition mediates KSRP regulation of let-7 biogenesis. Nat Struct Mol Biol 19: 1282-1286, 2012.

39. Sampson VB, Rong NH, Han J, Yang Q, Aris V, Soteropoulos P, Petrelli NJ, Dunn SP and Krueger LJ: MicroRNA let-7a downregulates MYC and reverts MYC-induced growth in Burkitt lymphoma cells. Cancer Res 67: 9762-9770, 2007.

40. Viswanathan SR, Powers JT, Einhorn W, Hoshida Y, Ng TL, Toffanin S, O'Sullivan M, Lu J, Phillips LA, Lockhart VL, et al: Lin28 promotes transformation and is associated with advanced human malignancies. Nat Genet 41: 843-848, 2009.

41. Yamakoshi H, Kanoh N, Kudo C, Sato A, Ueda K, Muroi M, Kon S, Satake M, Ohori H, Ishioka C, et al: KSRP/FUBP2 is a binding protein of GO-Y086, a cytotoxic curcumin analogue. ACS Med Chem Lett 1: 273-276, 2010. 